\title{
Contribuição para o uso de lodo de estação de tratamento de água in natura como agregado miúdo em concretos de cimento Portland: Avaliação da consistência, massa específica, porosidade, absorção, resistência à compressão e tração na compressão diametral
}

\author{
Contribution to the use of wet sludge water treatment \\ plant fine aggregate in Portland cement concretes: \\ Evaluation of consistency, density, porosity, absorption, \\ strength and tensile strength
}

Rúbia Meert ${ }^{1}$, Daniel Hastenpflug ${ }^{1}$, Jairo José de Oliveira Andrade ${ }^{2}$

\footnotetext{
${ }^{1}$ UFSC, Universidade Federal de Santa Catarina, Rua Dona Francisca, 8300, Bloco U, Zona Industrial Norte, CEP: 89219-600, Joinville,SC, Brasil.

${ }^{2}$ PUCRS, Av. Ipiranga, 6681 - Prédio 30, Partenon, CEP: 90619-900, Porto Alegre, RS, Brasil.

e-mail: rubia.meert@gmail.com, daniel.h@ufsc.br, jairo.andrade@pucrs.br
}

\begin{abstract}
RESUMO
O tratamento de água para consumo gera uma grande quantidade de resíduos, o lodo de estação de tratamento de água (LETA). Normalmente, estes rejeitos são depositados em rios e em outros locais da natureza, gerando impactos ambientais tais como assoreamento, alteração da fauna e da flora local. Para colaborar com a mitigação desta prática, este estudo verificou a influência do uso do lodo de ETA, in natura, como substituição da areia natural em concretos de cimento Portland, nos teores de 0\%, 5\%, $10 \%$ e $20 \%$, em massa. Para avaliar os efeitos causados pela incorporação do Lodo de ETA nas propriedades do concreto no estado fresco foram realizados os ensaios de abatimento do tronco de cone. Já no estado endurecido, foram conduzidos testes que observaram a porosidade aberta, a massa específica, a absorção de água, a resistência à compressão e à tração por compressão diametral. Verificou-se uma redução (de até 50\%) da consistência do concreto à medida que se aumentava o teor de substituição. A porosidade aberta também aumentou conforme o incremento do teor de lodo de ETA. Devido a isto, ocorreu uma redução na massa específica dos traços e um incremento na absorção de água ao se aumentar a quantidade de resíduo. A resistência à compressão média, aos 7 dias, reduziu 31,45\% quando se empregou 5\% de lodo, 41,52\% com $10 \%$ e 63,89\% com $20 \%$. Aos 28 dias, a resistência diminuiu 26,88\% os menores teores e 59,78\% para quantidades maiores. Já aos 91 dias, a capacidade portante foi 28,52\% (para o uso de 5\% de lodo), 40,33\% (10\% de resíduo) e 57,01\% (20 de lodo de ETA) menores, respectivamente. A resistência à tração por compressão diametral, aos 28 dias de idade, seguiu a mesma tendência, ocorrendo uma redução de $29,06 \%$ em concretos com $5 \%$ de lodo e $65,98 \%$ com substituição de $20 \%$ de resíduo. De forma geral foi possível observar que o lodo de ETA tem grande potencial de aplicação à construção civil, apresentando um teor limite de aplicação de 10\%, como agregado miúdo, sem gerar grandes prejuízos nas propriedades físicas e mecânicas.
\end{abstract}

Palavras-chave: Concreto; Lodo de ETA; Consistência, Resistência à compressão, Resistência à tração.

\section{ABSTRACT}

The treatment of drinking water generates a large amount of waste, the sludge from the water treatment plant (WTS). These tailings are usually deposited in rivers, which can generate environmental impacts. As a way of using this waste, the present study evaluates the influence of the use of WTS, in natura, as a substitute for natural sand in Portland cement concretes, at levels of $0 \%, 5 \%, 10 \%$ and $20 \%$, by weight. In order to evaluate the influence of the incorporation of WTS on the properties of the cementitious material in the fresh state, the slump tests were performed. In the hardened state, porosity, density, water absorption, strength and tensile strength by diametrical compression There was an increasing reduction (up to 50\%) in the flowability of the 
concrete as the substitution content increased. Also, constant increases in the porosity of the samples were noticed when the WTS was added. As a consequence, there was a reduction in the density of the concretes and an increase in water absorption. The strength at 7 days decreased from $31,45 \%$ when $5 \%$ sludge was used, $41,52 \%$ with $10 \%$ and $63,89 \%$ with $20 \%$. At 28 days, the resistance decreased $28,52 \%$ to the lowest levels and $65,98 \%$ to the highest amounts of WTS. At 91 days, the load capacity was 28,52\%, 40,33\% and $57,01 \%$ lower, respectively. The tensile strength followed the same trend, with a reduction of $29,06 \%$ in concretes with $5 \%$ of WTS and $65,98 \%$ with replacement of $20 \%$ of waste. In general, it was possible to observe that the WTS has great potential for application in civil construction, presenting a limit content of $10 \%$ as a fine aggregate, without causing major losses in physical and mechanical properties.

Keywords: Concrete; Sludge from the water treatment plant; Flowability; Strength; Tensile Strength.

\section{INTRODUÇÃO}

Com o crescimento das cidades, o consumo de água potável aumentou nas últimas décadas. Entretanto, devido a políticas públicas de gestão de mananciais ineficientes combinado com a falta de consciência sobre as questões ambientais, vem se observando a queda da qualidade da água bruta, sendo necessário o emprego de produtos químicos no processo de tratamento nas estações de tratamento de água (ETA). Estas práticas levam ao incremento da geração de resíduos sólidos. Estes produtos são comumente chamados de Lodo de ETA [1].

Durante o processo de tratamento de água comumente empregado, o lodo é produzido em dois momentos: na etapa de decantação e posteriormente na etapa de lavagem nos filtros [1]. Segundo CHÁVEZ PORRAS [2], o volume de lodo proveniente dos decantadores na ETA corresponde de $60 \%$ a $95 \%$ do total do lodo gerado. Já a água da lavagem dos filtros, de 5\% a $40 \%$.

De acordo com Nóbrega [3], o Brasil gera, em média, cerca de $762.500 \mathrm{~m}^{3} / \mathrm{dia}$ de resíduos nas ETAs convencionais. O lodo é gerado por 37,7\% dos municípios brasileiros geram lodo de ETA, e destes, 67,4\% descartam o resíduo em cursos hídricos, sem qualquer tratamento [4]. Comumente a disposição final deste resíduo acaba sendo em cursos d'água, aplicação no solo, disposição em aterro sanitário, incineração.

Buscando alternativas ambientalmente mais favoráveis, o emprego do lodo na construção civil pode ser uma possibilidade muito importante para a redução dos impactos ambientais da disposição inadequada, além de evitar a retirada de matérias primas naturais comumente empregadas [5, 6]. Diversos trabalhos apresentam a viabilidade do emprego do lodo de ETA na fabricação de cimento [7, 8] e tijolos [2, 9, 10], como agregados [1, 11-19] e como adições minerais [12, 13-23]

Para o emprego do lodo de ETA em materiais cimentícios, o lodo de ETA apresenta características químicas e físicas adequadas. Segundo ALEXANDRE et al. [8], a composição mineralógica deste resíduo é semelhante ao do cimento Portland (sílica, alumina e óxido de ferro) e em alguns casos pode possuir capacidade aglomerante devido a atividade pozolânica [20, 21]. Também apresentam características físicas tais como massa específica (apesar de mais leve), tamanho e forma de grão e distribuição granulométrica semelhantes a materiais já empregados na manufatura do concreto [8, 24].

Entretanto devido a quantidade significativa de matéria orgânica [12] apresentado no estado in natura, ou úmida, que variam de $16 \%$ a $32 \%$, muitos estudos acabam calcinando o resíduo para evitar os efeitos nocivos destes componentes [7, 10, 11]. RAMIREZ et al. [19] e HOPPEN et al. [13] constataram que a adição de até $20 \%$ de lodo calcinado propiciou aumento nas propriedades mecânicas do concreto. Em contra partida, verificou-se que a adição de lodo de ETA úmido reduziu em $25 \%$ a $68 \%$ a resistência do concreto.

Além de influenciar de maneira negativa as propriedades mecânicas, a necessidade do tratamento térmico acaba tornando o emprego do resíduo muito mais caro devido ao custo de energia necessário para a calcinificação. Isto prejudica o reaproveitamento do lodo de ETA que acaba não sendo explorado em todo o seu potencial.

Em função dos pontos aqui levantados, o presente trabalho tem como objetivo principal estudar a potencialidade do emprego do lodo de ETA como agregado miúdo em concretos de cimento Portland. Como objetivos específicos podem ser citados: (i) analisar as propriedades físico-químicas do lodo de ETA; (ii) verificar a influência da substituição de agregado miúdo por diferentes teores de lodo de ETA in natura avaliando propriedades físicas e mecânicas dos concretos, assim como questão de durabilidade a partir do ensaio de carbonatação.

\section{MATERIAIS E MÉTODOS}

A etapas do programa experimental estão representadas no fluxograma da Figura 1. 


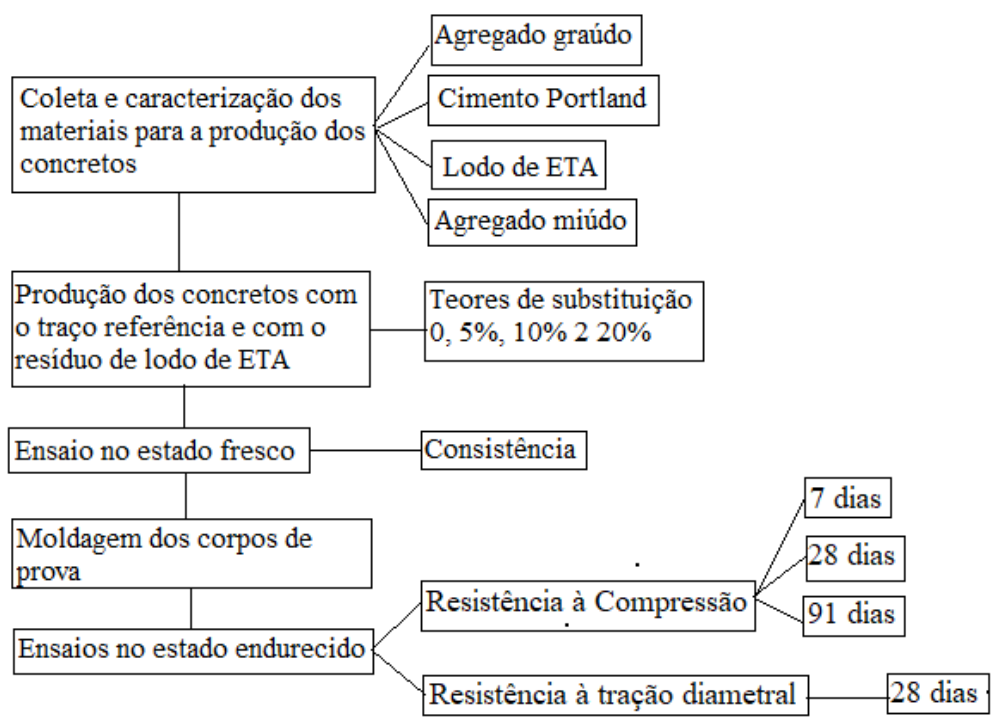

Figura 1: Esquema do programa experimental.

\subsection{Materiais}

Para o procedimento experimental foi utilizado o cimento Portland CP V ARI como aglomerante, cujo mesmo apresenta menor teor de adições quando comparado aos demais tipos de cimento. Na Tabela 1 estão apresentadas as características físicas do cimento, as quais todas atendem as prescrições exigidas na NBR 16697 [25].

Tabela 1: Caracterização física do cimento CPV ARI (Fonte: Fabricante, 2018)

\begin{tabular}{|c|c|c|}
\hline \multicolumn{2}{|c|}{ ENSAIO } & RESULTADO \\
\hline \multicolumn{2}{|c|}{ Resíduo \#200 } & $0,0 \%$ \\
\hline \multicolumn{2}{|c|}{ Resíduo \#325 } & $0,9 \%$ \\
\hline \multicolumn{2}{|c|}{ Expansibilidade à quente } & 0,4 \\
\hline \multicolumn{2}{|c|}{ Peso específico } & $3,1 \mathrm{~g} / \mathrm{cm}^{3}$ \\
\hline \multicolumn{2}{|c|}{ Superfície específica } & $5038 \mathrm{~cm}^{2} / \mathrm{g}$ \\
\hline \multirow{4}{*}{$\begin{array}{c}\text { Resistência } \\
\text { mecânica (MPa) }\end{array}$} & 1 dia & 24,4 \\
\hline & 3 dias & 34,8 \\
\hline & 7 dias & 40,4 \\
\hline & 28 dias & 48,5 \\
\hline
\end{tabular}

O lodo de ETA empregado foi coletado da estação de tratamento de água (ETA) Cubatão, localizada na cidade de Joinville (SC). O material coletado estava em seu estado pastoso, úmido, e foi utilizado nos concretos dessa forma, sem sofrer qualquer tipo de tratamento.

Para realizar-se a caracterização físico-química do resíduo, utilizou algumas técnicas apontadas por BRAGAGNOLO e KORF, [24] como adequadas para a análise de resíduos a serem empregados como agregados em concreto. Foram realizados os ensaios de Fluorescência de Raios-X (FRX), Difração de raiosX (DRX), Massa específica e Distribuição granulométrica.

Para isto, homogeneizou-se o material contido no tambor e retiraram-se 6 amostras, que passaram por um processo de secagem a fim de possibilitar a caracterização física e química do resíduo, cujo processo se deu em uma estufa a $105^{\circ} \mathrm{C}$ por $24 \mathrm{~h}$ (Figura 2). Observou-se que a umidade média destas amostras foi de $67 \%$, determinada conforme a NBR 9939 [26]. 


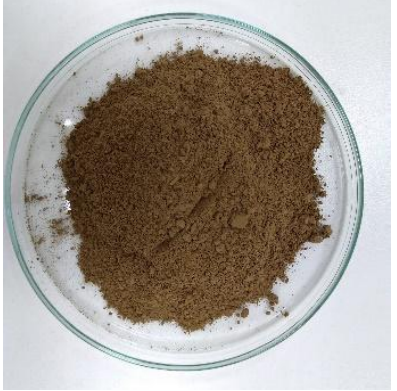

(a)

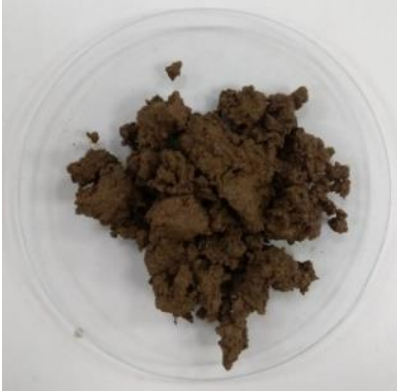

(b)

Figura 2: (a) Lodo seco em estufa; (b) Lodo in natura.

Apenas uma destas amostras do lodo foi posteriormente moído em um moinho de molas (39 bolas de 14 mm e 17 bolas de $20 \mathrm{~mm}$ ) por 7 minutos a uma rotação de $380 \mathrm{rpm}$. A composição química foi obtida a partir do ensaio de Fluorescência de Raios-X (FRX), realizado no equipamento Philips modelo PW 2400 cujo resultado está apresentado na Tabela 2. Pôde-se verificar a o elevado percentual de Alumina $\left(\mathrm{Al}_{2} \mathrm{O}_{3}\right)$ e Sílica $\left(\mathrm{SiO}_{2}\right)$, bem como o percentual de perda ao fogo, na amostra analisada.

Tabela 2: Composição química lodo da ETA pelo FRX.

\begin{tabular}{c|c|c|c|c|c|c|c|c|c|c|c|c}
\hline Óxidos & $\mathbf{A l}_{2} \mathbf{O}_{3}$ & $\mathbf{C a O}$ & $\mathbf{F e}_{2} \mathbf{O}_{3}$ & $\mathbf{K}_{2} \mathbf{O}$ & $\mathbf{M g O}$ & $\mathbf{M n O}$ & $\mathbf{N a}_{2} \mathbf{O}$ & $\mathbf{P}_{2} \mathbf{O}_{\mathbf{5}}$ & $\mathbf{S i O}_{2}$ & $\mathbf{S O}_{3}$ & Outros & $\mathbf{P . F}$ \\
\hline Teor $(\%)$ & 25,44 & 0,50 & 7,15 & 0,62 & 0,70 & 0,11 & 0,28 & 0,31 & 25,61 & 0,52 & 0,91 & 37,85 \\
\hline
\end{tabular}

Os valores mais expressivos são os de $\mathrm{Al}_{2} \mathrm{O}_{3}$, no teor de $25,44 \%$, e o $\mathrm{SiO}_{2}$, de $25,61 \%$. Enquanto o primeiro é gerado pelo uso de sulfato de alumínio como coagulante, enquanto o segundo indica a presença de materiais argilosos e areia contido na água bruta. Ambos os teores são equivalentes aos encontrados na literatura $[1,5,8,11-13,18,19,23,24,27-30]$.

A quantidade de $\mathrm{Fe}_{2} \mathrm{O}_{3}$ observado também é semelhante as referências bibliográficas estudadas. Este teor é observado devido aos produtos utilizados no processo de tratamento da água e da quantidade de hidróxido de ferro dos solos onde a fonte de água se localiza [31].

Segundo GERALDO et al. [32] e DOS SANTOS et al. [12], resíduos calcinados ou procedimentos de moagem, com altos teores de $\mathrm{SiO}_{2}$ e de $\mathrm{Al}_{2} \mathrm{O}_{3}$ apresentam potencial para o desenvolvimento de atividade pozolânica, assim como as adições minerais tradicionais, tais como cinza volante, metacaulim e sílica ativa. No caso do lodo de ETA, GASTALDINI et al. [20], FRÍAS et al. [21] apontam que é comum este tipo de resíduo apresentar propriedades aglomerantes.

Entretanto, neste estudo não foi avaliado se existe atividade pozolânica do lodo empregado na confecção dos concretos. Apesar de não verificado, conforme os resultados apresentados no ensaio de FRX, o material utilizado neste trabalho não apresenta os requisitos químicos, ditados pela NBR 12653 [33], necessários para gerar a pozolanicidade.

A presença de materiais carbonáceos e orgânicos influencia de maneira significativa as propriedades dos materiais cimentícios, tanto no estado fresco como no endurecido [22]. A perda ao fogo contabiliza a mitigação da quantidade de matéria, em massa, devido a perda de água de materiais argilosos e da volatilização de materiais orgânicos e carbonários [18, 34]. No lodo empregado neste trabalho, são observados em quantidade significativa (37,85\%). Esta quantidade está de acordo com os estudos consultados neste trabalho, que variam de 30 a $50 \%$ [13, 27].

Para identificação das fases cristalinas presente no lodo de ETA, a composição mineralógica foi determinada através do ensaio de Difração de raios-X (DRX), no equipamento marca Shimadzu, modelo XRD-6000. A varredura foi executada de $10^{\circ}$ a $90^{\circ}$ sendo $2^{\circ} / \mathrm{min}$, em amostras secas de lodo $\left(105^{\circ} \mathrm{C}\right.$ ) (Figura 3). Foram identificadas fases cristalinas de quartzo, calcita, hematita, leucita, anatásio e sulfato de zircônia, justificando a aplicabilidade do lodo de ETA como agregado em materiais cimentícios. Esta composição está de acordo com a literatura estudada, em GASTALDINI et al. [20] no lodo estudado foi identificado que o resíduo é composto em maior parte por quartzo e caulinita e, em menor quantidades, por feldspatos e hematita. Já GODOY [7] encontrou também picos de quartzo e caulinita, além de traços de muscovita e monganite. BUSELATTO et al. [11] verifica a presença de quartzo. 


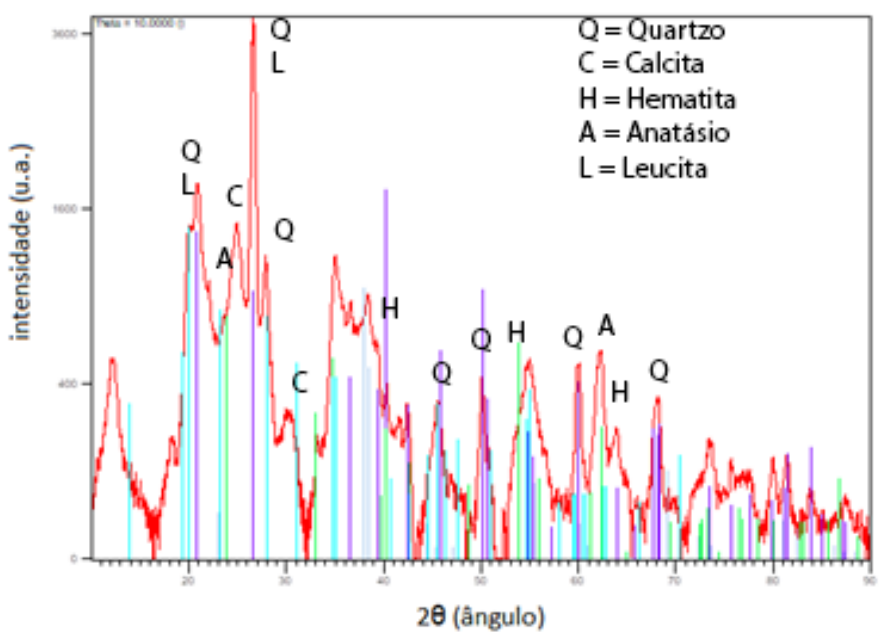

Figura 3: Difração de raios-X do lodo de ETA .

Como agregado miúdo, foram utilizados uma areia de britagem média de origem basáltica e o lodo de ETA. Já como agregado graúdo, uma brita com dimensão máxima característica de 12,7 mm e com módulo de finura 6,5. As características físicas destes materiais, assim como os métodos empregados para sua determinação, estão listadas na Tabela 3.

Tabela 3: Características físicas dos agregados empregados

\begin{tabular}{c|c|c|c|c}
\hline ENSAIO & MÉTODO & $\begin{array}{c}\text { AGREGADO } \\
\text { GRAÚDO }\end{array}$ & $\begin{array}{c}\text { AGREGADO } \\
\text { MIÚDO }\end{array}$ & $\begin{array}{c}\text { LODO DE } \\
\text { ETA }\end{array}$ \\
\hline $\begin{array}{c}\text { Massa especifica } \\
\left(\mathrm{g} / \mathrm{cm}^{3}\right)\end{array}$ & $\begin{array}{c}\text { NBR NM 52 [35] } \\
\text { NBR NM 53 [36] }\end{array}$ & 2,83 & 2,66 & 2,08 \\
\hline DMC (mm) & NBR 248 [37] & 12,7 & 2,36 & 0,125 \\
\hline Módulo de Finura & NBR 248 [37] & 6,53 & 2,55 & 0,30 \\
\hline
\end{tabular}

Para a determinação de sua distribuição granulométrica, foi empregado as prerrogativas da NBR 248 [37] e as curvas estão representadas nas figuras 4 e 5.

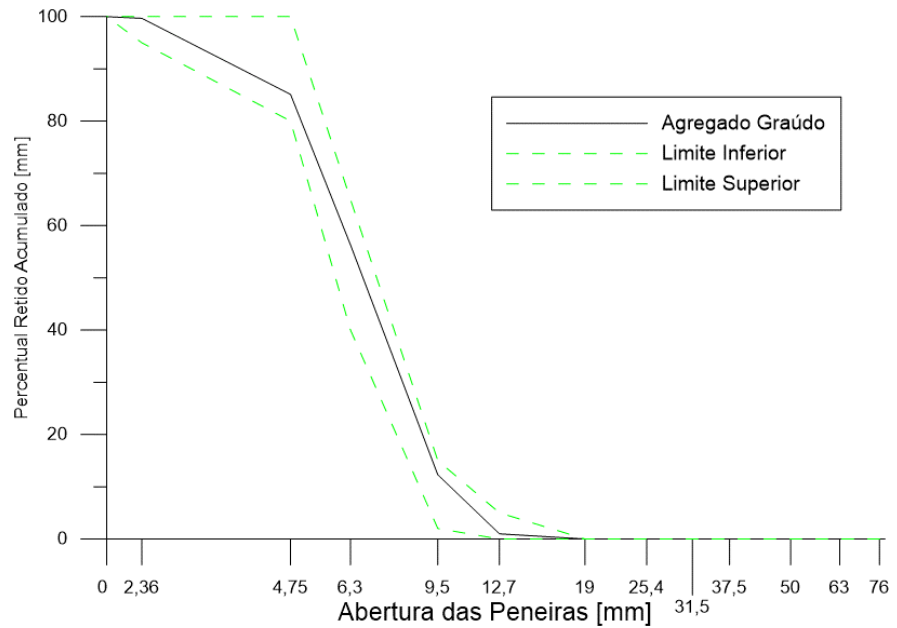

Figura 4: Curva granulométrica da brita. 


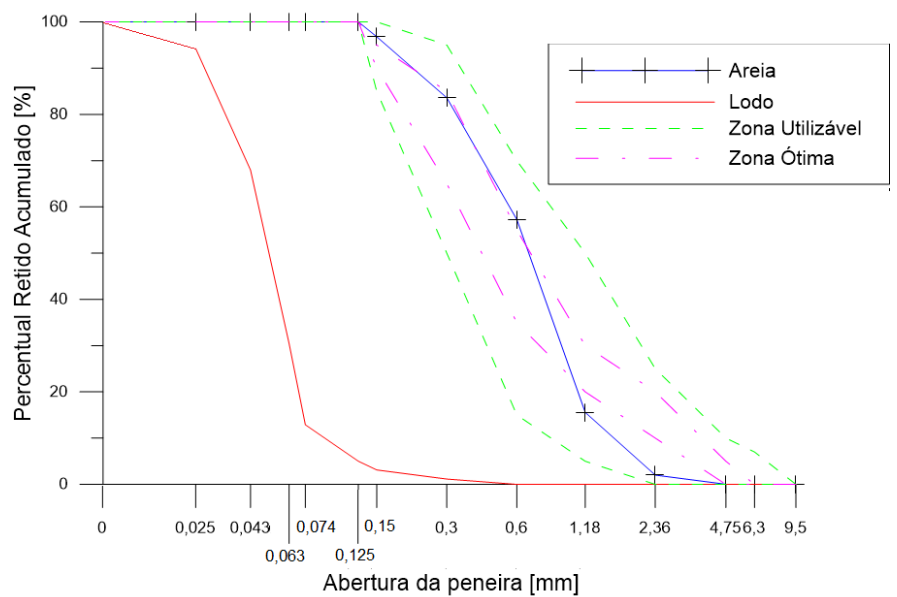

Figura 5: Curva granulométrica do lodo de ETA e da areia empregada no trabalho.

Observando, para os agregados miúdos, as curvas granulométricas, os valores de módulo de finura e dimensão máxima característica, pode-se afirmar que o lodo in natura empregado neste estudo era constituído de partículas muito mais finas que a areia previamente utilizada. Isto leva um aumento da superfície específica das partículas a serem empregadas, o que leva a um atrito maior entre as partículas, no estado fresco, provocando a necessidade de uma maior quantidade de água para determinada trabalhabilidade [34, 38].

Outro fator que pode afetar o desempenho do material é a massa específica. Verifica-se que a areia a ser substituída apresenta uma densidade maior do que o lodo. Segundo METHA e MONTEIRO [34] e NEVILLE [38] estes resultados mostram que o os componentes do lodo são mais leves do que o agregado miúdo convencional. Também pode indicar que os resíduos são mais porosos que o agregado normalmente empregado e com isso a trabalhabilidade e a resistência do concreto são afetados [24]. A substituição, em massa, como maior massa específica, por outro com menor, leva a um incremento da quantidade de partículas presentes na suspensão e um aumento do volume do material cimentício.

\subsection{Traço dos concretos}

No projeto experimental foram definidos três teores de substituição de agregado miúdo natural pelo lodo de ETA, (5\%, 10\% e 20\% em massa). Nesse caso, uma consideração importante deve ser realizada: como o lodo de ETA foi empregado na condição úmida nas misturas, a quantidade de água contida no resíduo foi descontada da água de amassamento estabelecida para a relação água/cimento (a/c) de 0,43 se mantivesse constante. Para tanto foi considerado para todas as dosagens, o teor de umidade do lodo, na condição úmida, igual a $67 \%$, determinado durante a caracterização do lodo e antes da realização dos traços testados. Vale ressaltar que o lodo permaneceu estocado em um tonel, o que fez com a umidade não apresentasse variação.

Para a dosagem de concreto foi adotado o método CIENTEC, apresentado por Recena [39]. Para obtenção do traço de referência foram considerados parâmetros e materiais específicos como dados de entrada para desdobramento do traço, cujos mesmos estão apresentados na Tabela 4.

Tabela 4: Parâmetros de entrada para desdobramento do traço

\begin{tabular}{c|c}
\hline RESISTÉNCIA CARACTERISTICA DO CONCRETO Á \\
COMPRESSÃO (FCK) & $40 \mathrm{MPa}$ \\
\hline RELAÇÃO ÁGUA/MATERIAIS SECOS (H) & $10,20 \%$ \\
\hline TEOR DE ARGAMASSA (a) & $60 \%$ \\
\hline
\end{tabular}

Depois de estabelecido o traço unitário para o traço de referência (REF), foram introduzidos parcialmente diferentes teores de lodo de ETA nas demais dosagens de concreto como substituição parcial do agregado miúdo, conforme apresentado na Tabela 5. 
Tabela 5: Traços adotados

\begin{tabular}{c|c|c|c|c|c|c}
\hline NOME & $\begin{array}{c}\text { CIMENTO } \\
{[\mathrm{Kg} / \mathbf{m} 3]}\end{array}$ & $\begin{array}{c}\text { AREIA } \\
{[\mathrm{Kg} / \mathbf{m} 3]}\end{array}$ & $\begin{array}{c}\text { LODO DE } \\
\text { ETA }[\mathrm{Kg} / \mathbf{m} 3]\end{array}$ & $\begin{array}{c}\text { BRITA } \\
{[\mathrm{Kg} / \mathbf{m} 3]}\end{array}$ & A/C & $\begin{array}{c}\text { ÁGUA } \\
{[\mathrm{KG} / \mathbf{m} 3]}\end{array}$ \\
\hline REF & 518,51 & 797,43 & 0 & 877,30 & 0,43 & 222,96 \\
\hline F05 & 518,51 & 757,56 & 39,44 & 877,30 & 0,43 & 196,53 \\
\hline F10 & 518,51 & 717,69 & 79,31 & 877,30 & 0,43 & 169,82 \\
\hline F20 & 518,51 & 637,94 & 159,06 & 877,30 & 0,43 & 116,39 \\
\hline
\end{tabular}

No estado fresco, foi realizado o ensaio de abatimento do tronco de cone conforme a norma NBR NM 67 [40] para a verificação da consistência do concreto. Em nenhum dos materiais cimentícios avaliados ocorreu segregação ou exsudação.
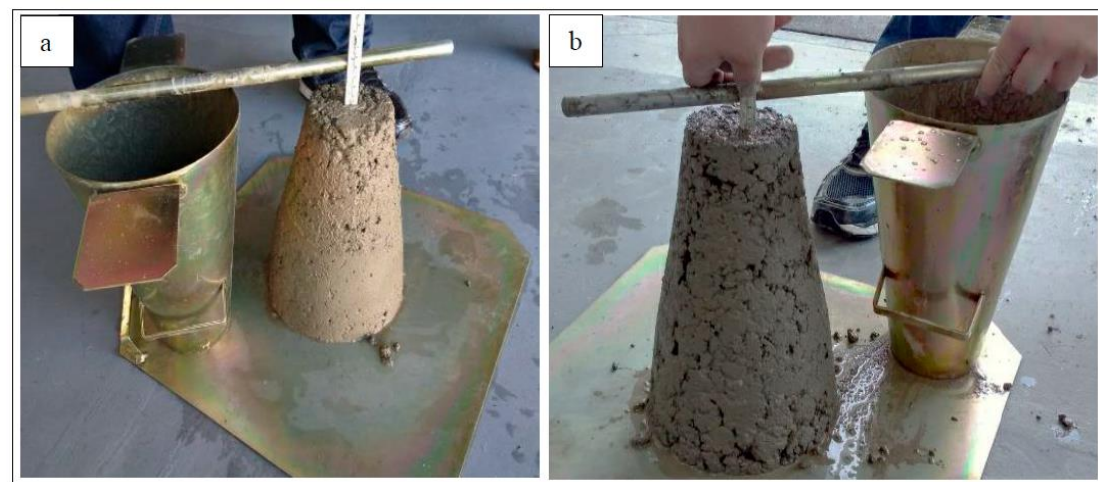

Figura 6: Ensaio do abatimento do tronco de cone a) Concreto Referência; b) Concreto com substituição de areia por lodo de ETA em $10 \%$.

Para confecção dos concretos, foi utilizada uma betoneira de capacidade de 120 litros sendo confeccionado ao todo 21 corpos de prova por traço. Todas os quatro traços (REF, F05, F10 e F20) foram executados em um mesmo dia e em uma só mistura por traço.

Os ensaios realizados nos corpos de prova de concreto confeccionadas foram executados tomando como base normas técnicas, conforme segue na Tabela 6 . A cura dos corpos de prova ocorreu à temperatura ambiente nas primeiras 24 horas, e imersa no restante dos dias.

Tabela 6: Normas, quantidade de corpos de prova e idades dos ensaios realizados

\begin{tabular}{lccc}
\hline \multicolumn{1}{c}{ ENSAIO } & NORMA TÉCNICA & № CPS & IDADES \\
\hline Absorção d'água por imersão & NBR 9778 [41] & 3 & 28 dias \\
Massa específica & NBR 9778 [41] & 3 & 29 dias \\
Porosidade & NBR 9778 [41] & 3 & 30 dias \\
Resistência à compressão & NBR 5739 [42] & 3 & 7,28 e 91 dias \\
Resistência à tração por compressão diametral & NBR 7222 [43] & 3 & 28 dias \\
\hline
\end{tabular}

\section{RESULTADOS E DISCUSSÃO}

\subsection{Consistência}

Os resultados obtidos no ensaio de abatimento do tronco de cone (NBR NM 67 [40]), apresentados na tabela 7, mostram que a incorporação de lodo de ETA levou a redução do abatimento. A substituição de 5\% de areia por resíduo levou a uma redução do abatimento de $50 \%$, enquanto a emprego de $10 \%$ lodo alterou a consistência em 52,5\% enquanto o maior teor, o valor a consistência ficou 62,5 menor que o concreto referência. 
Tabela 7: Resultados do Ensaio de Abatimento do Tronco de Cone

\begin{tabular}{c|c|c|c|c}
\hline TRAÇO & REF & F05 & F10 & F20 \\
\hline CONSISTÊNCIA [mm] & 40 & 20 & 21 & 25 \\
\hline
\end{tabular}

HOPPEN et al. [13] e FERNANDEZ et al. [23] empregaram lodos de estação de tratamento de água em teores que variaram de $3 \%$ a $10 \%$, em massa, em substituição de areia e afirmam que a fluidez se reduz conforme o incremento de lodo e a redução da umidade. A utilização de teores de $10 \%$ leva a uma redução de cerca de 50\% do abatimento do tronco do cone. RABIE et al. [14], JAMSHIDI et al.[15] e ALQEDRA et al. [16] observaram que o emprego de lodos de estação de tratamento de esgoto in natura como substituição de areia geram a redução do abatimento do tronco de cone em 50\%, quando comparado ao concreto referência, ao se usa um teor de 5\% de substituição. Para teores maiores (10 - 20\%) essa mitigação da consistência varia de $50 \%$ a $53 \%$

Esta redução do abatimento dos concretos com lodo de ETA é devida as características físicas do lodo e a alteração da distribuição granulométrica dos agregados miúdos. Devido a escolha deste trabalho, em substituir a areia pelo lodo, nos teores de $5 \%, 10 \%$ e $20 \%$, em massa, a quantidade de material empregado nessa substituição foi cerca de $19 \%$ maior do que caso o mesmo fosse substituído em volume. Isto ocorre porque o lodo tem uma massa específica $\left(2,08 \mathrm{~g} / \mathrm{cm}^{3}\right)$ menor do que a da areia média utilizada $\left(2,66 \mathrm{~g} / \mathrm{cm}^{3}\right)$. Desta maneira, aumentou-se a quantidade de partículas, o que eleva a demanda de água da mistura para que se alcance a mesma trabalhabilidade [34, 38]. Além disso, partículas finas tendem a formar aglomerados de partículas quando entram em contato com a água, assim aprisionam a água de amassamento da mistura [44, 45].

Outro fator que colabora para a mitigação de água disponível na mistura é a matéria orgânica presente no lodo de ETA. Estes compostos aumentam a coesão das partículas devido a formação de coloides, que promovem uma viscosidade irregular do resíduo, aprisionando o solvente e impedindo que o mesmo esteja disponível para todo o concreto $[14,15]$.

Também contribui para a redução da fluidez do concreto é o tamanho das partículas dos agregados. Novamente, a substituição da areia, com módulo de finura 2,55, por um material mais fino, que é o lodo (M.F de 0,30$)$ fez aumentar a superfície específica dos grãos e consequentemente mais atrito entre as partículas $[34,38]$.

Em relação a distribuição granulométrica, sabe-se que quanto mais contínua for, melhor será o desempenho do material, tanto no estado fresco quanto no endurecido. Esta continuidade permite uma maior eficiência do empacotamento das partículas [34]. Verifica-se na Figura 7, quanto maior a quantidade de lodo incorporado como agregado miúdo, a curva de distribuição granulométrica se torna cada vez menos bem distribuída e se afastando das zonas ótima e utilizável [46], desta maneira, prejudicando o empacotamento das partículas e consequentemente, o desempenho dos concretos no estado fresco.

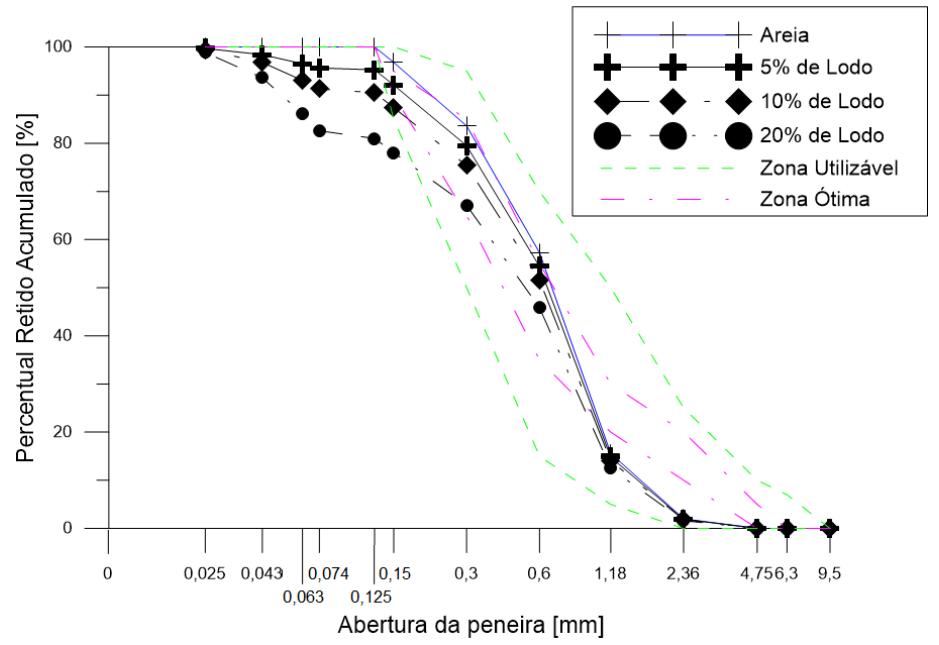

Figura 7: Distribuição granulométrica das mesclas de areia com lodo de ETA. 


\subsection{Propriedades físicas}

Os resultados referentes às propriedades físicas estão apresentados na Figura 8. É possível observar que com o acréscimo de lodo de ETA, houve também um acréscimo na porosidade do concreto, logo, uma redução na sua massa específica e por consequente, um aumento na absorção de água.

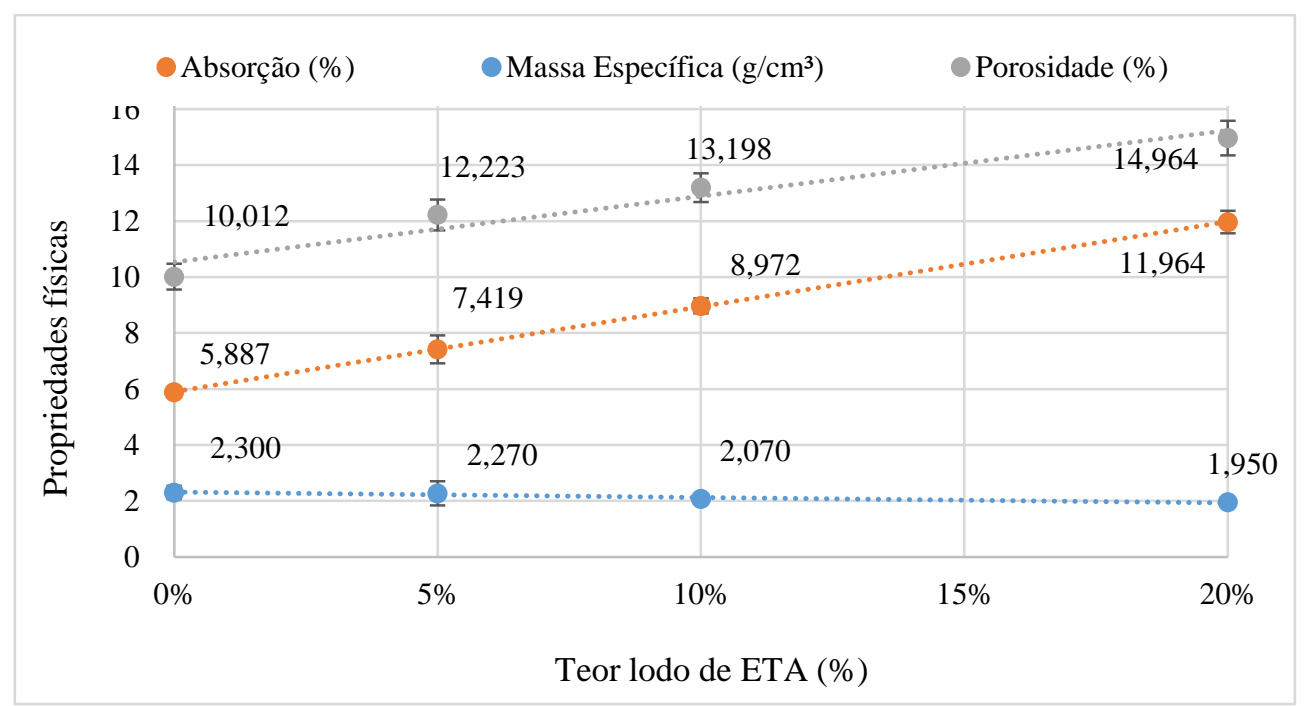

Figura 8: Influência do teor de lodo de ETA nas propriedades físicas.

Observa-se que, comparando F05 com REF há uma redução de 2,19\% da massa específica, um aumento de $19,08 \%$ da porosidade e uma elevação da absorção de água de 26,02\%. Da mesma forma com F10, tem-se uma queda de $13,54 \%$ da massa específica, uma elevação de $11,12 \%$ na porosidade e de $52,40 \%$ na absorção de água. Por fim, constata-se uma redução de $26,54 \%$ da massa específica de F20 em relação a REF, um aumento de $33,14 \%$ da porosidade e de $103,22 \%$ da absorção de água.

A variação da massa específica se dá pela própria substituição da areia pelo lodo, que é um material mais leve. Quanto maior o teor de substituição, menor vai ser o peso específico do concreto. Isto ocorre devido as características físico-químicas do lodo e a distribuição granulométrica da mescla de agregados miúdos.

O lodo é composto de minerais e matérias orgânicas que possuem uma microestrutura porosa do lodo e da sua composição mineralógica que resultam em um material mais leve (massa específica $\left(2,08 \mathrm{~g} / \mathrm{cm}^{3}\right)$ quando comparado com a areia $\left(2,66 \mathrm{~g} / \mathrm{cm}^{3}\right)[17,34]$.

Já as granulometrias dos agregados miúdos (areia e lodo de ETA) estudadas mostram que quanto maior o teor de lodo, e consequentemente de finos, menos contínua é a sua distribuição. Desta maneira, ao se aumentar a quantidade de resíduo da mistura faz com que a curva granulométrica seja muito diferente da ideal, o que leva a um aumento dos vazios da mistura, visto que as partículas mais finas e a matéria orgânica formaria grumos que aprisionariam a água de amassamento, resultando, posteriormente, em vazios de diâmetros maiores, podendo ou não ser intercomunicados [44, 45, 47]. Conforme observa-se na Figura 9, nos concretos estudados neste trabalho verifica-se que quanto menor a massa específica, maior a porosidade do material cimentício. 


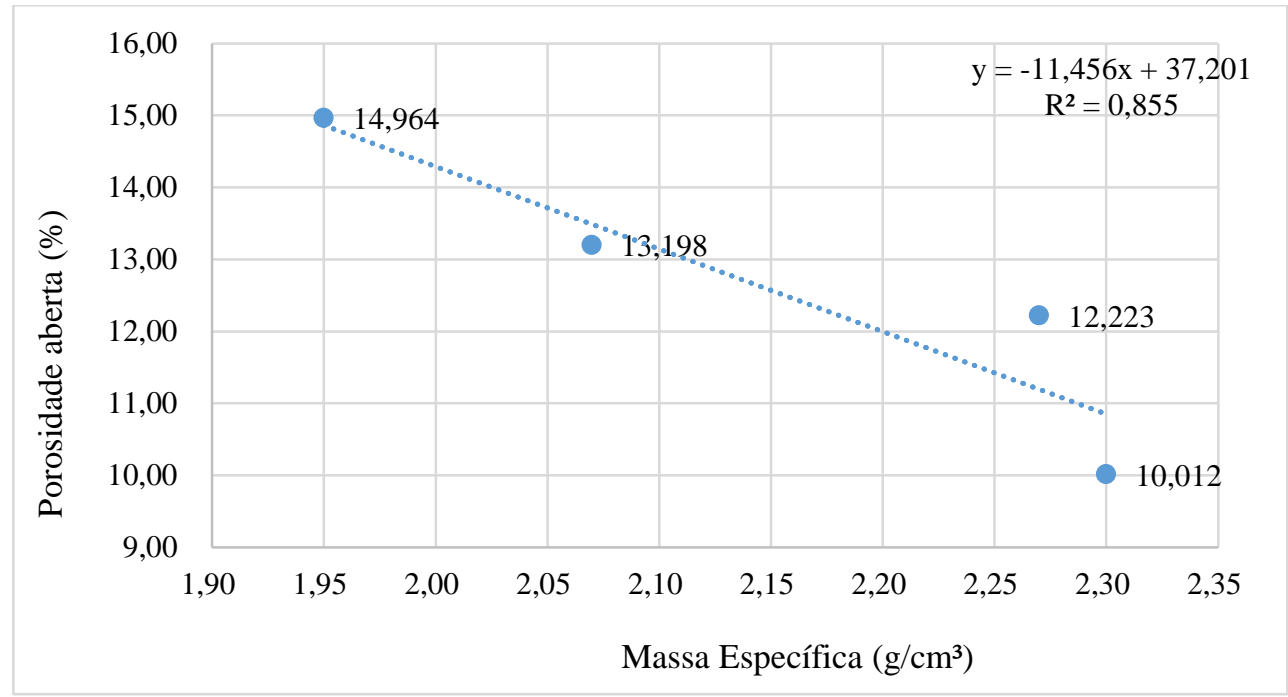

Figura 9: Relações entre Porosidade e Massa Específica dos concretos testados.

A redução da massa específica conforme o incremento do teor de lodo também foi observado em outros trabalhos da literatura. Usando lodos de ETA in natura, HOPPEN et al. [13], a substituição de 3\% a 10\% de areia resultou numa redução desta propriedade de 5,92\% a 6,30\%. Empregando lodo calcinado, por SOUZA [48], RAMIREZ et al. [1, 19] e TAFAREL et al. [18] observaram que quanto maior o teor de substituição de areia por resíduo, menor a massa específica.

A porosidade de um concreto é influenciada pela composição dos seus componentes e de sua estrutura de poros. Devido aos resultados observados, acredita-se que a distribuição granulométrica da combinação areia e lodo de ETA leva a uma quantidade de vazios intergranulares maiores conforme o emprego de teores mais elevados de resíduo. A formação de grumos por causa do aumento da quantidade de finos e de matéria orgânica também contribui para a formação de mais poros, e estes com diâmetros maiores.

A absorção de um concreto é influenciada diretamente pela quantidade e o tamanho dos diâmetros dos poros da sua microestrutura [34, 49, 50]. Além destes fatores, segundo AHMAD et al. [17], o aumento da absorção de água dos concretos confeccionados com lodo de ETA também é devido a porosidade da matéria orgânica presente no resíduo. Nos concretos testados neste trabalho, pode-se verificar uma relação proporcional entre a porosidade e absorção de água (Figura 10), onde uma maior porosidade gera uma absorção de água mais elevada, visto que quanto mais vazios, mais facilitada é a entrada e percolação da água no concreto.

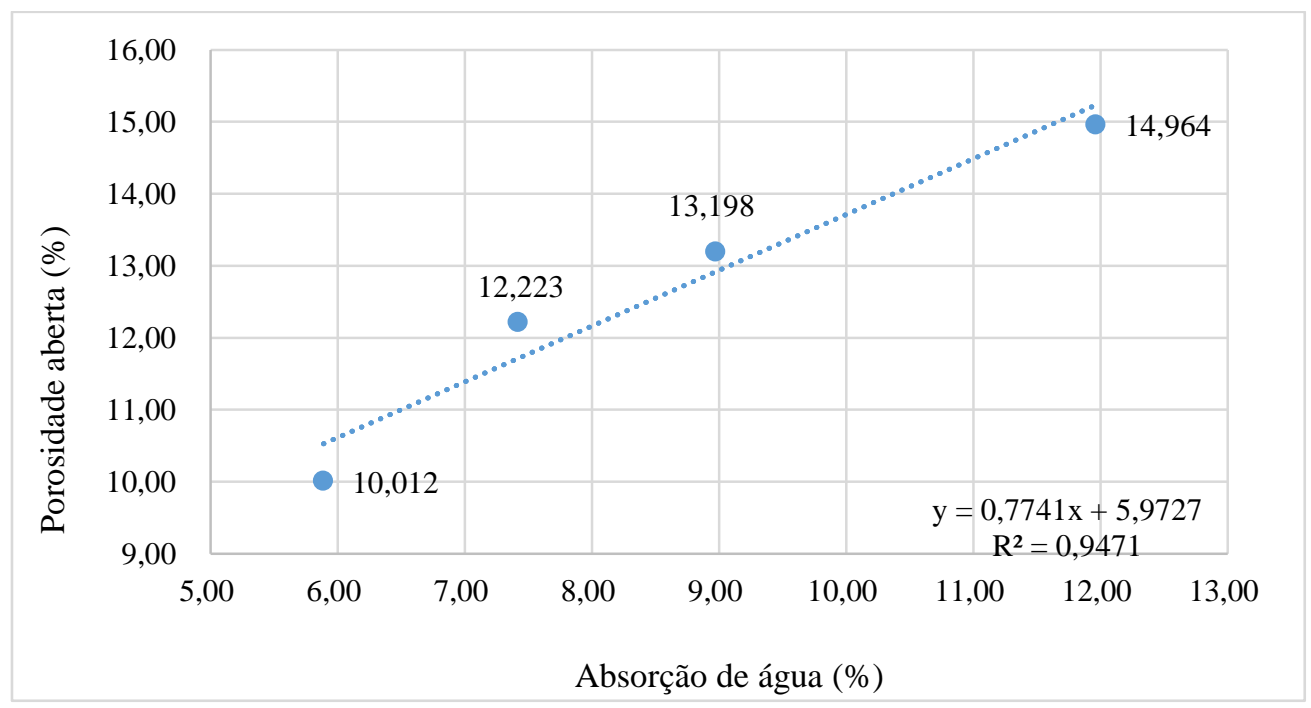

Figura 10: Relações entre Porosidade e absorção dos concretos testados. 
A mesma tendência em relação a porosidade e a absorção observada neste trabalho foi verificada por HOPPEN et al. [13] que para a substituição de agregado miúdo por teores de $3 \%$ a $10 \%$ lodos de ETA in natura observou um incremento de porosidade na faixa de $1,67 \%$ a $14,38 \%$ e consequentemente, um aumento de absorção de 8,68\% a 25,21\%. BUSELATTO et al.[11] SOUZA [48], RAMIREZ et al. [1, 19] e TAFAREL et al. [18], com lodos calcinados como agregado miúdo como substituição do agregado miúdo, observaram o emprego de cerca de $10 \%$ de lodo, levou a um aumento em torno $30 \%$ na absorção. Já a porosidade aumentou $32,7 \%$ para o mesmo teor.

A maioria dos processos de degradação dos materiais cimentícios que afetam a durabilidade estão relacionadas a presença de água na microestrutura. Desta maneira, a porosidade e a absorção de um concreto, assim como intercomunicação entre os poros e a permeabilidade afetam de maneira significativa a vida útil do material [34, 45, 51, 52].

HELENE [52] classifica como muito durável um concreto que apresenta absorção de água inferiores a 4,2\%. Já materiais com esta propriedade com valores superiores a 6,3\% são considerados deficientes. Concretos com valores de absorção entre 4,2\% e 6,3\% são considerados compostos cimentícios com durabilidade normal. Já a International Tunnelling Association [53] estabelece que absorção entre $8 \%$ e $9 \%$ indica que o material possui qualidade tolerável.

Desta maneira, segundo critérios apontados por HELENE [52], os concretos com o emprego de lodo de ETA como agregado miúdo, testados neste trabalho apresentam indícios de não apresentarem durabilidade satisfatório devido a absorção ter um valor maior do 6,3\%. Já quando avaliou-se usando os critérios da International Tunnelling Association [53], somente os concretos que empregam o teor de $20 \%$ de lodo ETA como agregado não apresenta o requisito de absorção para ser classificado como qualidade tolerável. Independente das classificações anteriores, para que o material seja empregado em campo, é necessário a condução de testes de durabilidade a ambientes nocivos e verificado o comportamento do material a longo prazo.

\subsubsection{Resistência à Compressão}

Na Figura 11 estão apresentados os resultados de resistência à compressão, podendo-se verificar a tendência de crescimento ao longo do tempo, independente do teor de lodo de ETA incorporado na mistura. Quando se verifica a influência da presença deste resíduo, nota-se que existe um decréscimo de resistência conforme a quantidade de lodo presente na mistura aumenta. Estes comportamentos também foram verificados por outros autores $[11,17,18,19,48]$.

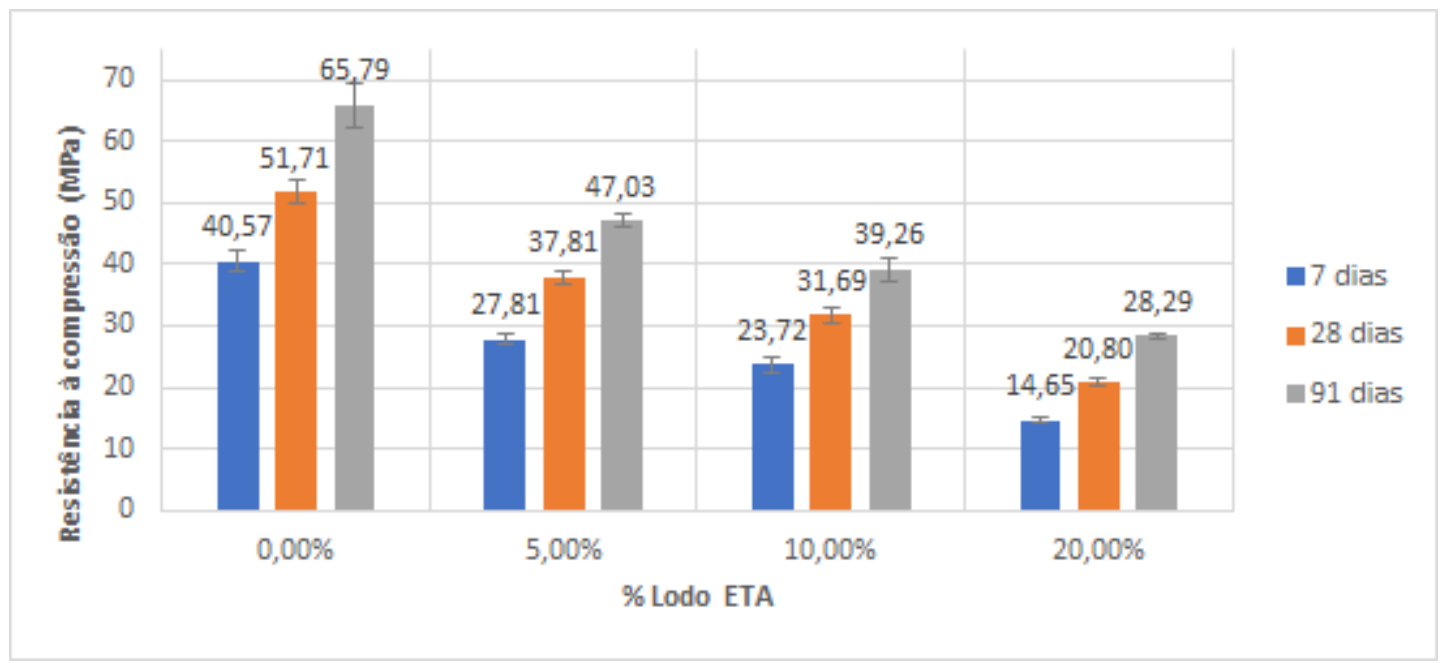

Figura 11: Influência do teor de lodo de ETA na resistência à compressão dos concretos.

Para 7 dias, os concretos F05, F10 e F20 apresentaram resistências 31,45\%, 41,53\% e 63,88\% menores que o concreto REF. Aos 28 dias, os mesmos traços chegaram a capacidades portantes 26,88\%, 38,71\% e $59,77 \%$ menores que o concreto referência. Já aos 91 dias, observou-se uma redução de 28,51\%, 40,32\% e $56,99 \%$, respectivamente.

Os trabalhos de HOPPEN et al. [13], TAFAREL [18], YAGÜE, et al. [54] e FERNANDEZ [23] também apresentaram as mesmas tendências de variação de resistência à compressão do presente estudo. A substituição de areia por lodo de ETA in natura, em teores de 5\% fez com a resistência a compressão 
reduzisse na faixa de $11,37 \%$ a25\%. Já o emprego de $10 \%$ do resíduo determinou capacidade portante $29 \%$ a $68 \%$ menores.

Em estudos que empregavam o lodo de ETA calcinado como agregado a mesma tendência de redução da resistência também foi observado. Já SOUZA [48] e RAMIREZ et al. [19], verificaram um aumento da resistência dos concretos quando substituiu a areia por lodo de ETA em teores que variaram até $10 \%$. Aos 28 dias, no concreto com teor de $2 \%$ lodo apresentou uma resistência $27 \%$ superior ao concreto de referência.

A resistência à compressão está relacionada com a quantidade e as características dos componentes (agregados, aglomerantes, água) e da porosidade da microestrutura. Observa-se a redução desta propriedade nos concretos com a substituição de areia por lodo de ETA primeiramente, pela matéria orgânica presente no lodo in natura [16, 22]. Outro fator que contribui para a mitigação da resistência é a natureza porosa da matéria orgânica [17], que consequentemente tem capacidade de carga menor [16, 22, 34, 50].

Sabe-se que conforme a porosidade de um concreto aumenta, a tendência da sua resistência à compressão é diminuir [34, 38]. Como observando no item 3.2, a porosidade dos concretos estudados foi influenciada pelo aumento da quantidade de partículas finas (lodo de ETA), que tornaram a distribuição granulométrica dos agregados miúdos menos contínua, o que resultou em maiores quantidades de vazios intergranulares. Esta quantidade maior de frações de diminutas dimensões, junto com a matéria orgânica presente no resíduo, também contribui para a formação de grumos e o aprisionamento de água, que em idades mais avançadas resultaram em vazios $[1,11,14,15,17-19,22]$.

Outro fator que influenciou a resistência à compressão foi a forma da substituição, em massa, de areia por lodo de ETA. Como a massa específica do lodo é menor do que a areia, a substituição da mesma massa, leva a um aumento de $19 \%$ de resíduo caso fosse realizado essa substituição em volume. Esta nova mescla de agregados possui uma quantidade maior de grãos para o mesmo consumo de cimento, o que prejudica o empacotamento das partículas a adesão entre os grãos, contribuindo para a redução da resistência dos materiais cimentícios testados. Além disso, uma quantidade maior de partículas finas na mistura, para uma mesma quantidade de água, gera uma redução na trabalhabilidade do concreto, o que pode dificultar o adensamento do concreto e consequentemente prejudicar sua resistência à compressão [14-16].

Observando o aspecto químico, sabe-se que a presença de matéria orgânica em agregados miúdos pode influenciar de maneira nociva no desenvolvimento de resistência do concreto ao longo do tempo, pois ocasiona o aumento do tempo de início de pega, atrasando a formação dos produtos de hidratação [12, 18, 34, 38].

Segundo a NBR 8953 [55], concretos com resistência características à compressão inferiores a $20 \mathrm{MPa}$ não são consideradas estruturais. Para os concretos estudados, tendo em vista que a média do traço F20 atingiu um valor minimamente superior a $20 \mathrm{MPa}$ aos 28 dias de cura, levando em conta o desvio padrão $(1,20 \mathrm{MPa})$, esse valor pode ser minimamente inferior ao limite ideal de $20 \mathrm{MPa}$. Sabendo disso, priorizando a segurança e levando em conta apenas critérios mecânicos, conclui-se que teores maiores que $10 \%$ de lodo de ETA em relação a massa do agregado miúdo, não são recomendados à aplicação estrutural. Vale ressaltar que não se deve fazer uso de nenhum material em concretos estruturais avaliando somente a resistência à compressão dos compostos cimentícios. É necessária uma avaliação detalhada dos efeitos do emprego deste resíduo na durabilidade do concreto ao longo do tempo, principalmente em idades avançadas.

Frente a tudo que foi observado até então, os traços REF, F05 e F10 superaram a resistência à compressão mínima definida pela NBR 6118 [56] (20 MPa), alcançando valores superiores a $30 \mathrm{MPa}$ aos 28 dias de cura. Se considerar apenas a resistência à compressão, o lodo de estação de tratamento de água tem potencial uso em concretos aplicados à contrapisos, blocos de pavimento intertravado, peças decorativas, blocos e placas de vedação e entre outros sem função estrutural. Vale ressaltar que independente do uso, para se empregar o uso de lodo na confecção dos concretos, é necessário avaliar a durabilidade da matriz cimentícia, através de ensaios adequados, para se verificar se a presença deste lodo acarreta na aceleração de processos de degradação do concreto armado ou a lixiviação de elementos nocivos para o ambiente.

\subsubsection{Resistência à tração por compressão diametral}

Assim como na resistência à compressão, a resistência à tração por compressão diametral diminui com o acréscimo do lodo de ETA na mistura, conforme mostrado na Figura 12. Neste caso, as amostras foram ensaiadas apenas aos 28 dias de cura. Observa-se um decréscimo na resistência à tração de 29,06\% quando comparado F05 a REF e um decréscimo de 65,98\% quando comparado F20 a concreto referência. Estes valores mostram que a substituição de agregado miúdo por lodo influenciou a resistência à tração. 


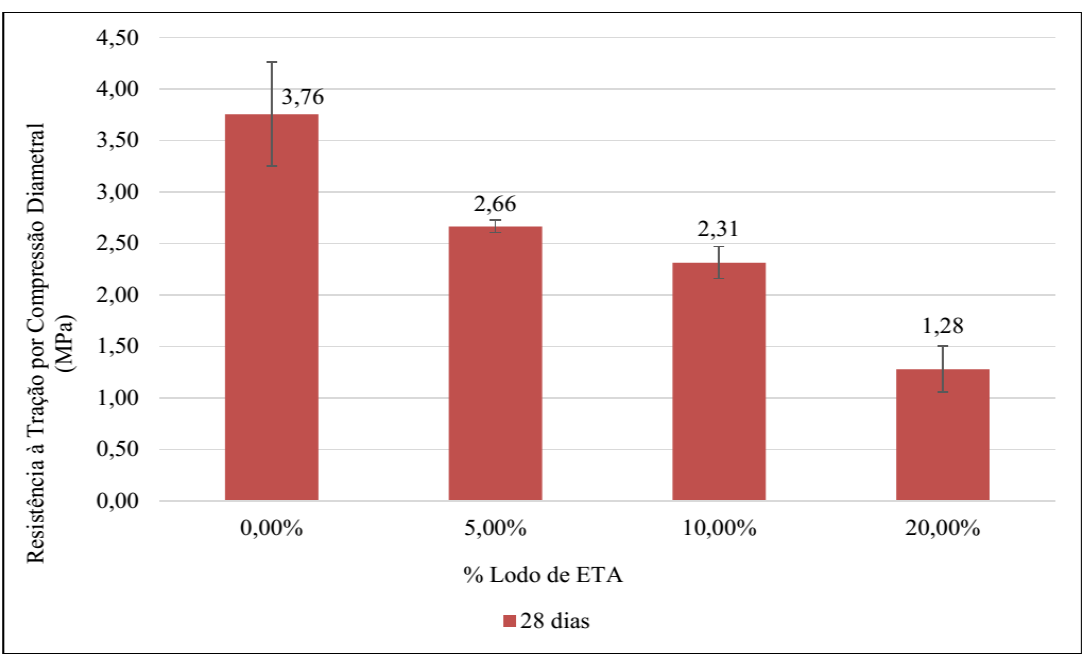

Figura 12: Influência do teor de lodo de ETA na resistência à tração diametral dos concretos.

Segundo os estudos de HOPPEN et al. [13], TAFAREL et al. [18], FERNANDEZ et al. [23] que concretos com substituição de areia por lodo em teores de $4 \%$ a $12 \%$, apresentam uma redução da resistência à tração por compressão diametral de $11 \%$ a $33 \%$. Para a substituição por lodo de ETA calcinado, BUSELATTO et al. [11] e SALES et al. [30] s apresenta uma redução na faixa de 20,7\% a 45,45\% da resistência à tração.

Já RAMIREZ et al. [19] observou que ao se adicionar lodo calcinado ao concreto, verificou-se um incremento de 13,5\% nos valores de resistência à tração na compressão diametral.

Segundo SCANDIUZZI e ANDRIOLO [57], a razão típica da resistência à tração por compressão diametral pela resistência à compressão axial é em torno de $7 \%$ a $8 \%$. Nos concretos testados neste estudo, observou-se que esta razão para os corpos de prova confeccionados observa-se que para REF esta razão foi de 7,26\%, para F05 de 7,05\%, F10 de 7,30\% e F20 de 6,14\%. Dessa forma é possível observar mais uma vez o teor limite ideal de lodo de $10 \%$ (F10). Em todas as referências bibliográficas consultadas apresenta, uma razão da resistência à tração pela resistência à compressão variando de 7 a $10 \%$.

Esta redução da resistência à tração é causada pelos mesmos fatores que prejudicam a resistência à compressão. A inclusão de um material mais viscoso, com módulo de finura menor e uma maior quantidade de partículas (lodo de ETA in natura), prejudica a dispersão do material de forma mais uniforme, dificultando a interação com o aglomerante e aumentando a probabilidade de regiões mais porosas [13-17, 34]. Outro fator que colabora para a redução desta resistência mecânica são a diferença de tamanho das partículas de areia e do lodo (menor) e a massa específica (mais leve). Um aumento da quantidade e da superfície específica dos grãos de agregado reduzem a fluidez do concreto, o que prejudica a qualidade do adensamento e consequentemente, o aumento de falhas de concretagem e do teor de vazios [11, 13-17, 22]. Por último, com a substituição de areia por lodo de ETA in natura leva ao aumento da quantidade de matéria orgânica presente no resíduo [16, 22].

\section{CONCLUSÃO}

A partir dos resultados obtidos com a substituição de areia por lodo de ETA in natura na matriz de concreto, foi possível concluir:

- O emprego de teores de 5\%, 10\% e $20 \%$ influencia nas propriedades dos concretos avaliados neste trabalho: massa específica, porosidade, absorção, resistência à compressão e a tração por compressão diametral.

- Quanto maior o teor de lodo utilizado, menor é a massa específica do concreto e, consequentemente, maiores são a porosidade e a absorção.

- A variação das propriedades mecânicas é diretamente afetada pela porosidade dos concretos e a quantidade de matéria orgânica. Conforme o aumento da quantidade de lodo empregado na mistura, maior vai ser a quantidade de vazios na matriz do concreto.

- A incorporação do lodo leva a uma redução da resistência à compressão do concreto conforme se aumenta a quantidade de lodo na mistura. Todos os teores empregados influenciam de maneira significativa, levando ao desenvolvimento de propriedades mecânicas menores quando comparadas com o concreto referência.

- Resistência à tração também é afetada negativamente devido ao emprego de lodo de ETA em concretos. 
- Avaliando apenas a resistência à compressão, para concretos com fins estruturais, teores inferiores a $10 \%$ poderiam ser utilizados. Em teores mais elevados, o lodo de ETA in natura como agregado miúdo deve ser utilizado para a confecção de elementos sem fim estrutural, tais como blocos e paredes de vedação, pavimentos intertravados, peças de decoração, entre outros.

- Para qualquer uso, recomenda-se novos estudos a respeito da estabilização dos componentes do lodo na matriz cimentícia, avaliando a durabilidade e a lixiviação de elementos nocivos.

- Também faz necessária a investigação para testar alternativas para empregar uma quantidade maior de lodo de ETA sem que ocorra a mitigação da resistência, tais como o emprego de aditivos redutores de água ou adições minerais. Além disso, deve-se realizar estudos de otimização do teor de lodo de ETA in natura, assim como a otimização do traço para gerar traços com maior consumo de resíduo e com mais econômicos para o fim desejado.

- O emprego de lodo de ETA gera benefícios em termos de preservação ambiental, visto que além de evitar que a disposição (adequada ou não) no ambiente, promove a redução da exploração de recursos naturais para a fabricação de agregados. O uso do resíduo em seu estado úmido também colabora com a mitigação do consumo de energia para a secagem. Em adição, verifica-se uma economia de custo, devido ao menor valor do rejeito em comparação com os agregados comumente empregados.

\section{BIBLIOGRAFIA}

[1] RAMIREZ, K.G. "Viabilidade do aproveitamento de resíduo de estação de tratamento de água (ETA) na confecção de concretos”, Dissertação M.Sc., PPGTAMB/UTFPR, Medianeira, PR, Brasil, 2015.

[2] CHÁVEZ PORRAS, A. "Uso de lodo de Estação de Tratamento de Água e agregado reciclado miúdo na fabricação de elementos de alvenaria”, Tese de D.Sc., PPGEC/ UNICAMP, Campinas, SP, Brasil 2007.

[3] NÓBREGA, C.C., PEREIRA, S.L.M.,BARBOSA, G., "Caracterização do lodo residual das lagoas de lodo da estação de tratamento de água - estudo de caso: ETA - Gramame”, In: Hacia la sustentabilidad: Los residuos sólidos como fuente de energía y materia prima, $4^{\circ}$ Simposio Iberoamericano de Ingeniería de Residuos (SIIR), 2011.

[4] DI BERNARDO, L., DANTAS, D.B.A, VOLTAN, P.E.N., Métodos e técnicas de tratamento e disposição dos resíduos gerados em estações de tratamento de água. 1 ed, São Paulo, Ldibe, 2012.

[5] LUCAS, D., BENATTI, C.T., "Utilização de resíduos industriais para a produção de artefatos cimentícios e argilosos empregados na construção civil”, Revista em Agronegócios e Meio Ambiente, v. 1, 2008.

[6] ANDRADE, C., MYNRINE, V., SILVA, D.A., et al. "Compósito para a construção civil a partir de resíduos industriais", Matéria, v.21, n.2, 2016.

[7] GODOY, L.G.G., "Incorporação de lodo de estação de tratamento de água (ETA) calcinado em cimento composto e pozolânico", Dissertação de M.Sc., FURV, Blumenau, SC, Brasil, 2018.

[8] ALEXANDRE, E., LUZ, C.A. "Substituição parcial do cimento CPV-ARI por lodo de estação de tratamento de água (ETA)”, Matéria, v.25, n.1, 2020.

[9] TARTARI, R., et al. "Lodo gerado na estação de tratamento de água Tamanduá, Foz do Iguaçu, PR, como aditivo em argilas para cerâmica vermelha: incorporação do lodo em mistura de argilas para produção de cerâmica vermelha", Cerâmica, v. 57, n. 344, 2011.

[10] KIZINIEVIČ, O., ŽURAUSKIENĖ, R., KIZINIEVIČ, V., et al., "Utilization of sludge waste from water treatment for ceramic products", Construction and Building Materials, v. 41,2013.

[11] BUSELATTO, D.M., WENZEL, M.C., ROCHA, G.H., et al. "Incorporação de lodo de estação de tratamento de água (ETA) como agregado miúdo em concretos: avaliação das propriedades físicomecânicas", Matéria, v. 24, 2019.

[12] SANTOS, G.Z.B, MELO FILHO, J.A., MANZATO, L. "Perspectivas de aplicações tecnológicas de lodo gerado no processo de tratamento de água dos rios Negro e Solimões”, Matéria, v.23, n.03, 2018.

[13] HOPPEN, C., PORTELLA, K., JOUKOSKI, A., et al. "Co-disposição de lodo centrifugado de Estação de Tratamento de Água (ETA) em matriz de concreto: método alternativo de preservação ambiental", Cerâmica, v. 51, 2005

[14] RABIE, G.M., EL-HALIM, H.A., ROZAIK, E.H., "Influence of using dry and wet wastewater sludge in concrete mix on its physical and mechanical properties", Ain Shams Engineering Journal, v. 10, 2019

[15] JAMSHIDI, A., MEHRDADI,, N., JAMSHIDI, M., "Application of Sewage Dry Sludge as Fine Aggregate in Concrete”, Journal of Environmental Studies, V,. 37, N. 59, Dec. 2011

[16] ALQEDRA, M., ARAFA, M., MATTAR, M. J., "Influence of Low and High Organic Wastewater Sludge on Physical and Mechanical Properties of Concrete Mixes", Journal of Environmental Science and Technology, v. 4, 2011.

[17] AHMAD, T., AHMAD, K., ALAM, M., "Sustainable management of water treatment sludge through 3'R' concept", Journal of Cleaner Production, v. 124, 2016. 
[18] TAFAREL, N.F., MACIOSKI, G., CARVALHO, K.Q., "Avaliação das propriedades do concreto devido à incorporação de lodo de estação de tratamento de água", Matéria, v. 21, n. 4, 2016.

[19] RAMIREZ, K.G., POSSAN, E., DEZEN, B.G., "Influência da adição de lodo de eta in natura e calcinado na produção de concreto", In: 57 O Congresso Brasileiro do Concreto, IBRACON, Bonito, 2015

[20] GASTALDINI, A.L.G., HENGEN, M.F., "The use of water treatment plant sludge ash as a mineral additionl", Construction and building materials, v. 94, 2015.

[21] FRÍAS, M., VIGIL DE LA VILLA, R., DE SOTO, I., et al., "Influence of activated drinking-water treatment waste on binary cement-based composite behavior: Characterization and properties, Composites Part B", Engineering, v. 60, 2014.

[22] RODRÍGUEZ, N.H., RAMÍREZ, S.M., VARELA, M.T.B. et al., "Re-use of drinking water treatment plant (DWTP) sludge: Characterization and technological behaviour of cement mortars with atomized sludge additions", Cement and Concrete Research, v. 40, 2010.

[23] FERNANDEZ, L.P., MIKOWSKI, P.C.B., MACIOSKI, G., et al. "Avaliação da incorporação do lodo de Estação de Tratamento de Água em peças de concreto intertravado". Matéria, v. 23, n. 03, 2018.

[24] BRAGAGNOLO, L., KORF, E.P. "Aplicação de resíduos na fabricação de concreto: como técnicas analíticas de caracterização podem auxiliar na escolha preliminar do material mais adequado?”, Matéria, v.25, n.1, 2020.

[25] ABNT. ASSOCIAÇÃO BRASILEIRA DE NORMAS TÉCNICAS. NBR 16697: Cimento Portland Requisitos. Rio de Janeiro: 2018.

[26] ABNT. ASSOCIAÇÃO BRASILEIRA DE NORMAS TÉCNICAS. NBR 9939: Agregado graúdo Determinação do teor de umidade total - Método de ensaio. Rio de Janeiro: 2011

[27] PORTELLA, K.F., ANDREOLI, C.V., HOPPEN, C., et al. "Caraterização físico-química do lodo centrifugado da estação de tratamento de água Passaúna-Curitiba/PR". In: Anais do $22^{\circ}$ Congresso Brasileiro De Engenharia Sanitária Ambiental. Joinville, 2003.

[28] DE RESENDE, D.S., BEZERRA, A.C.S., GOUVEIA, A.M.C., "Propriedades mecânicas de compósitos cimentícios produzidos com lodo de estação de tratamento de efluentes da indústria de batata pré-fritas", REM, Ouro Preto, v. 65, n.2, abr. jun., 2012.

[29] PERINI, L.R., DIAS, L.C., RECKZIEGEL, T., et al. "Estudo de aproveitamento do lodo da ETA de Santa Rosa", In: Anais do $5^{\circ}$ Congresso Internacional de Tecnologias para o Meio Ambiente Bento Gonçalves/RS, Brasil, 2016

[30] SALES, A., SOUZA, F.R., ALMEIDA, F.C.R.. "Mechanical properties of concrete produced with a composite of water treatment sludge and sawdust"., Construction and Building Materials, v. 25, 2011.

[31] ANDREOLI, C.V., MOTTA, A.C.V., FERNANDES, C.V.S., et al., "Disposição Final de Lodos de Estações de Tratamento de Água”, In: Lodo de Estações de Tratamento de Água - Gestão e Perspectivas Tecnológicas. cap. 2. pp. 68 -130. Curitiba, SANEPAR, 2013.

[32] GERALDO, R.H., FERNANDES, L.F.R., CAMARINI, G., "Water treatment sludge and rice husk ash to sustainable geopolymer production", Journal of Cleaner Production, v. 149, pp. 146-155, 2017.

[33] ABNT. ASSOCIAÇÃO BRASILEIRA DE NORMAS TÉCNICAS. NBR 12653: Materiais pozolânicos - Requisitos. Rio de Janeiro: 2015.

[34] MEHTA, P.K., MONTEIRO, P.J.M. Concreto. Microestrutura, Propriedades e Materiais. 2 ed. São Paulo. IBRACON. 2014.

[35] ASSOCIAÇÃO BRASILEIRA DE NORMAS TÉCNICAS. NBR NM 52 - Agregado miúdo Determinação da massa específica e massa específica aparente. Rio de Janeiro, 2009.

[36] ASSOCIAÇÃO BRASILEIRA DE NORMAS TÉCNICAS. NBR NM 53 - Agregado graúdo Determinação de massa específica, massa específica aparente e absorção de água. Rio de Janeiro, 2009.

[37] ASSOCIAÇÃO BRASILEIRA DE NORMAS TÉCNICAS. NBR NM 248 - Agregados - Determinação da Composição Granulométrica. Rio de Janeiro, 2003

[38] NEVILLE, A.M. Propriedades do concreto. 2. ed. São Paulo: Pini, 1997. 828 p.

[39] RECENA, F.A.P., "Método de Dosagem de Concreto pelo Volume de Pasta com Emprego de Cinza Volante", Tese de D. SC, PPGEC/UFRGS, Porto Alegre, RS, Brasil, 2011.

[40] ASSOCIAÇÃO BRASILEIRA DE NORMAS TÉCNICAS. NBR NM 67: Concreto - Determinação da consistência pelo abatimento do tronco de cone. Rio de Janeiro: 1998.

[41] ASSOCIAÇÃO BRASILEIRA DE NORMAS TÉCNICAS. NBR 9778: Argamassa e concreto endurecidos - Determinação da absorção de água por imersão - Índice de vazios e massa específica. Rio de Janeiro: 2009.

[42] ASSOCIAÇÃO BRASILEIRA DE NORMAS TÉCNICAS. NBR 5739: Concreto - Ensaio de compressão de corpos de prova cilíndricos. Rio de Janeiro: 2018.

[43] ASSOCIAÇÃO BRASILEIRA DE NORMAS TÉCNICAS. NBR 7222: Argamassa e Concreto - 
Determinação da resistência à tração por compressão diametral de corpos de- prova cilíndrico. Rio de Janeiro: 2011.

[44] HERMANN, A., LANGARO, E.A., LOPES DA SILVA, S.H., et al. "Empacotamento de partículas de cimento e sílica ativa em pastas pelo uso de modelo analítico", Revista Ibracon de Estruturas e Materiais, v. 9 , n. 1, 2016.

[45] LOPES, H.M.T., PEÇANHA, A.C.C., CASTRO, A.L. "Considerações sobre a eficiência de misturas de concreto de cimento Portland com base no conceito de empacotamento de partículas". Matéria, v.25, n.1, 2020.

[46] ASSOCIAÇÃO BRASILEIRA DE NORMAS TÉCNICAS. NBR 7211 Agregados para concreto Especificação. Rio de Janeiro: 2009.

[47] LÓPEZ, D.A.R., AZEVEDO, C.A.P., BARBOSA NETO, E., “Avaliação das propriedades físicas e mecânicas de concretos produzidos com vidro moído como agregado fino”, Cerâmica, v. 51, 2005.

[48] SOUZA, F.R.D., "Estudo da eco-eficiência de argamassas e concretos reciclados com resíduos de estações de tratamento de água e de construções e demolições”. Dissertação M. Sc, PPGEC/UFSCar, São Carlos, SP, Brasil, 2006.

[49] ROSSETTO, M. "Desenvolvimento de geopolímeros com a adição do lodo de Estações de Tratamento de Água.”. TCC (Graduação) - Curso Civil de Engenharia de Infraestrutura/UFSC, Joinville, SC, Brasil, 2017.

[50] TRENTIN, P.O., MANICA, J., VANZETTO, S.C., et al. "Substituição parcial de agregado miúdo por resíduo de vidro moído na produção de argamassa”, Matéria, v.25, n.1, 2020.

[51] BATTAGIN, A.F., Concreto: Ciência e Tecnologia, 2 ed, São Paulo, IBRACON, 2011.

[52] HELENE, P.R.L., "La Agressividad del Medio y la Durabilidad del Hormigón”, Hormigón, AATH. n. 10 , pp. 25-35, ago. 1983 .

[53] INTERNATIONAL TUNNELLING ASSOCIATION., "Shotcrete for rock support: a summary reportof the state of the art in 15 countries", Tunneling and Underground Space Techonology. v.8, n.4, pp. 441-470, 1993.

[54] YAGÜE, A., VALLS, S., VÁZQUEZ, E., et al. "Durability of concrete with addition of dry sludge from wastewater treatment plants", Cement and Concrete Research, v. 35, 2005.

[55] ASSOCIAÇÃO BRASILEIRA DE NORMAS TÉCNICAS. NBR 8953: Concreto para fins estruturais Classificação pela massa específica, por grupos de resistência e consistência. 3 ed. Rio de Janeiro: 2015.

[56] ABNT. ASSOCIAÇÃO BRASILEIRA DE NORMAS TÉCNICAS. NBR 6118: Projeto de estruturas de concreto - Procedimento. Rio de Janeiro: 2014

[57] SCANDIUZZI, L., ANDRIOLO, F. R. Concreto e seus materiais: propriedades e ensaios, 1. ed, Pini, São Paulo, 1986.

\section{ORCID}

Rúbia Meert

Daniel Hastenpflug

Jairo José de Oliveira Andrade https://orcid.org/0000-0002-7025-9566

https://orcid.org/0000-0002-8469-5756

https://orcid.org/0000-0003-2073-6763 